\title{
The Contextual over the Referential in Military Translation
}

\author{
Musallam Al-Ma'ani ${ }^{1}$ \\ ${ }^{1}$ Department of English, Sultan Qaboos University, Muscat, Oman \\ Correspondence: Musallam Al-Ma'ani, P. O. Box 42, Department of English, Sultan Qaboos University, Muscat, \\ Oman. E-mail: musallam@squ.edu.om
}

Received: May 13, 2015 Accepted: July 26, 2015 Online Published: July 28, 2015

doi:10.5539/elt.v8n8p199 URL: http://dx.doi.org/10.5539/elt.v8n8p199

\begin{abstract}
Dictionaries of all types, monolingual or bilingual, specialized or general, form the basic tools for both undergraduate translation students (UTSs) and professional translators (PTs). However, it is generally accepted that the difference between UTSs and PTs is that UTSs normally over-rely on dictionaries, which produces unsatisfactory results. For it is not only the lexical meaning provided by dictionaries that is important in translation, but also the contextual meaning. Hence, it is the USTs' ability to translate and use specialized terms/words appropriately within the context of situation and, by extension, within the larger world of the text, which is crucial. The aim of the article is to address issues related to Arabic military translation. In particular, it focuses on the long-standing relationship between specialized terms and translation and how terms may influence the UTSs' quality and accuracy, given that Arabic suffers from difficulties in handling and standardizing specialized technical terms. Data were drawn from translations by undergraduate students at Sultan Qaboos University in Oman. The analysis shows that students faced problems at understanding technical information as well as technical terms and collocations. It was also noted that two of the better bilingual dictionaries turned out to be of little help. The examples discussed provide pointers to the challenges that would face UTSs when handling technical translation in their early careers.
\end{abstract}

Keywords: technical translation, context, reference, specialized terms, professional translators, bilingual dictionaries, military abbreviations

\section{Introduction}

Handling unfamiliar words/terms is one of the important differences between students of translation and professional translators. It is generally accepted that students normally rely on dictionaries, particularly bilingual dictionaries, whereas professional translators use dictionaries, monolingual or bilingual, "as a stimulus to the process of refining meaning and selecting an appropriate rendering" (Fraser, 1993). In his study of technical translation in undergraduate programmes, Al-Ma'ani (2012) reports the difficulties of teaching this type of translation at the undergraduate level in the Arab world, especially when a teacher-centred approach is adopted in the classroom. He argues that, given the interdisciplinary nature of technical translation, a single academic course cannot include all the technical fields. And again even when technical translation courses are offered, the problem still exists on selecting the most important field the course should cover.

Taking target text (TT) production as a yardstick for judging translation appropriateness, Al-Ma'ani (2012) argues the TT can be assessed in terms of both its structural aspects, comprising problems of morphology and syntax (from phrase to discourse), and lexical categories, involving words in use and terminology management. How technical information is communicated in the recipient culture is governed more by the overall situation in which translation is carried out. The acceptability of translated technical information lies in the way translators handle various elements that closely affect the purpose of translation, target text audience, and knowledge of the subject matter. Within these parameters, specialized terms come into play and form an essential part of technical translation, because they constitute an element that is "a highly sensitive substance since it is the sign of knowledgeability and technical competence and even the slightest error may have quite impressive consequences" (Gouadec, 2007).

However, in a classroom setting, where students are asked to produce translations of technical texts, the problem of specialized terms and their appropriate equivalents in the target language (TL) becomes the main concern for undergraduate translation students (UTSs). The decisions UTSs make are not influenced by their familiarity with 
the subject and its associated terms, but simply by the use of specialized dictionaries. The unsatisfactory translation results can be ascribed to a number of reasons:

1) UTSs, at this stage, are still in the process of not only learning translation methods and approaches, but also learning the foreign language and improving their native one through and in conjunction with translation.

2) Because dictionaries in the Arab world are not updated regularly, there is little wonder that UTSs encounter words which have still not been arabicized. Technical terms are often unavailable in Arabic and the lack of standardized terms in Arabic constitute a hurdle even for PTs, let alone UTSs.

3) The multidisciplinary nature of the technical genre makes it difficult for UTSs to become informed in all its domains. Byrne (2012) argues that there are "numerous different types of texts used to communicate scientific and technical information, and most of them in a constant state of change. Each text has its own characteristics and content and is generally produced for a particular purpose." He further groups the majority of technical texts under the following headings: manuals, applications and proposals, reports, scientific papers, presentations, regulatory documents and popular science. This diverse nature makes it difficult for (1) course designers and instructors to combine these texts in a single undergraduate course, and (2) students to master them all and remain informed of all the subjects that come under such a typology.

4) UTSs still lack subject matter knowledge. Al-Ma'ani (2011) emphasizes the importance of subject matter for translators as there is always dissatisfaction with the products of scientific and technical translations, which he attributes to the translators' failure to appreciate the amount of knowledge necessary for this kind of discourse. It is common to find students who are not familiar with technical subjects, despite the fact that "specialized knowledge has increasingly spread over the whole community: parcels of knowledge (mechanics, economics, law, medicine...) which were exclusive to specialists have become common ground for larger segments of population and are found in everyday communication" (Asensio, 2007). In this regard, Schmitt (2005) argues that detecting ambiguities and having the ability to formulate the problems is largely dependent on having pertinent expertise about the domain one is translating in. This is true of military texts, where translators need to possess an acceptable knowledge-base that enables them to manage military translation crises in different situations.

5) UTSs do not realize how sensitive technical translation can be. In this regard, Al Ma'ani (2012) argues that in actual translation situations "inaccurate translation of technical documents might have disastrous and detrimental effect to those whose action depends entirely on the material translated into the TC [target culture]. A mistake in the translation of a technical document cannot be compared, for example, to a mistake in translating a novel."

6) Technical translators working in real situations do not only face different types of texts, but also a broad spectrum of readers of different backgrounds, qualifications and professions. That is why translation students need to learn to deal with different situations to meet the needs of this wide and varied audience. In this regard, one should distinguish between novice translation students, PTs, and their audience. Because in a classroom activity the audience to whom the students' work is addressed remains imaginary, they should be given a detailed brief which should, according to Nord (2005), contain explicit or implicit information about the intended function(s) of the text, the audience targeted by the translation, the time and place where the target text is received, the medium through which the text will be conveyed, and the motive for the production or reception of the text. This is why UTSs should pay special attention to specialized terms, especially when translating specialized technical texts (STTs) because in actual situations translators come across technical terms which may or may not have come across them before.

\section{Data}

An incident report on a Jaguar aircraft of the Royal Air Force of Oman (RAFO) was the text chosen for an experiment in military translation, being a branch of scientific and technical translation (see Appendix 1). Technical in nature, this text reflects the type of text translators normally handle in actual situations. And because the students were not familiar with the subject matter, they could replicate the kind of reality experienced by PTs. The text was published in the RAFO Flight Safety Magazine (1998), known locally as al-Ma'amoon. As it is a bilingual magazine, English and Arabic versions were both used. The production and reception of both English and Arabic texts were identical. The situation including time, place and motive, under which the English source text (ST) and Arabic target text (TT) were produced, was almost the same. That is the same technical and textual organization aspects were maintained in the English and Arabic versions. 
The text was given to the students in a typical translation classroom, where the teaching normally goes through a procedure in which students' linguistic and technical progress normally relies on error correction by instructors, an approach akin to what Kiraly (2000) calls 'a teacher-centred approach to translation'. Because it was assumed that the aim of producing the TT would be the same as that of the original English text, the students were told not to express their opinion on the issue or to reflect on the content. They also had to follow the same layout, including the textual organization and composition of the original text.

Since the ST was directed to a specific category of audience; not only RAFO pilots but other pilots flying the same aircraft elsewhere in the world, the students had also to consider this while translating. If the audience of the TT was different from that of the original ST, then the translation would consider the amount of the readers' previous knowledge about the objects and phenomena referred to. The students had also the opportunity to discuss their translations with their colleagues, consult mono/bilingual dictionaries, but they still had to finish the translation within the prescribed time for class.

The text was given to students enrolled in Sultan Qaboos University (SQU) undergraduate translation programme in their seventh semester. As part of the programme, the students were introduced to professional aspects of translation early in their study. The text was given to the spring 2011 semester students taking a course called "Scientific and Technical Translation." This course focuses on the varieties of scientific and technical language and intensive practice is given in the translation of texts of this type from and into English and Arabic. In this course, students normally embark on translating a variety of topics ranging from scientific articles, covering various areas of scientific discourse, to product catalogues and various manuals. The course also covers pertinent translation strategies and techniques to enhance students' understanding of basic technical/scientific terms and style through practical translation work. Pre-translation analysis, post-translation editing and proofreading are all highlighted and thoroughly discussed with the students. The students, too, had a preconceived notion of translation, focusing on: language(s) involved and their relevance to translation and transfer competence including text analysis, problem spotting and solving. While translating the text, the students used two bilingual English-Arabic dictionaries: The Unifying Military Dictionary (1971) and A New Dictionary of Scientific and Technical Terms (1975). The first is a military dictionary, the only comprehensive English-Arabic military dictionary used in Arab military circles, whereas the latter is a technical dictionary that is commonly used for technical translation in the Arab world.

\section{Analysis and Discussion}

An analysis of the various components of the ST shows that it uses abbreviations and terms associated with a specific problem encountered in aircraft. As the subject is relatively new to both Arabic language and culture, the available military/technical dictionaries, including The Unifying Military Dictionary and A New Dictionary of Scientific and Technical Terms, do not contain a number of terms and abbreviations, such as surge, bleed valve light, TGT, FL. These are essential terms given the nature of the text. Students were expected to maintain the ST technical nature, as the information in it would be incomprehensible for a person who does not know engineering or is unfamiliar with flying and aeronautical matters.

Because finding appropriate technical terms in Arabic is the main concern of this study, the analysis focuses on two perspectives. The first involves the ability of the students to handle specialized terms by consulting technical dictionaries and their ability to render the terms appropriately, given the text's context. The main difference between the former and the latter is that the former requires an effective use of the dictionary whereas with the latter, in addition to the dictionary, the students should have the ability to fit the selected words into the textual context.

Analysis of the students' translations shows that they were unable to render new technical words/terms or find appropriate equivalents to others whose meanings depend primarily on context. This is because translating technical texts is more difficult than translating general or everyday texts.

The first problem the students faced was that they were unable to choose between technical and non-technical terms, especially when a single word in the source language (SL) has different equivalents in the target language (TL). For example, a sentence like After 5-10 minutes the pilot felt some vibration was rendered by the students as وبعد مضي 5 إلى 10 دقائق راود الطيار بعض التردد This sentence, when back translated into English, reads: After 5 to

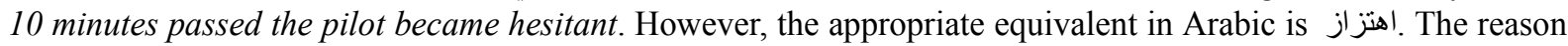

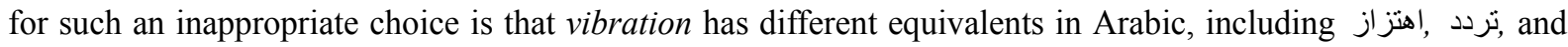
نبذبة But, because the students lacked the technical knowledge, they chose the inappropriate word literally means hesitation.

Another example is the verb departed, which can be translated into Arabic as غادر, 
technical, whereas the latter is more general and can be used in all situations except the context above. Similarly, the word leader can be rendered into Arabic as زيائد (ي) The former can be used in political contexts only, whereas in Arabic the latter can be used in both military and political contexts.

There are also terms which can be used within military situations but have different meanings in Arabic depending on the context in which the word is used. An example is the word landing. Within the military context, this word can be used to refer to an act of landing by an aircraft or an amphibious vehicle. However, two different words are used in Arabic to distinguish each type of landing. If the landing is made by an aircraft the word هبوط is used, but if it is made by an amphibious vehicle the word إنزال is used instead. So, whether an Arabic translator will choose the word هبوط or in a particular instance depends on the situation and technical background of the translator. In this text, the students used the word هبرط إنز latter is the appropriate equivalent for this context. This is a typical problem in technical texts where finding appropriate lexical equivalents seems to be achieved by making choices between two or more terms. The translator has to rely on the context of situation to determine the appropriate equivalent for the term involved as Neubert (2000) claims that the meaning of a ST word is equivalent within the framework of the text only because the text is regarded as a unit of meaning rather than separate words and structures.

Also, the students could not understand new technical word strings or collocations or find appropriate equivalents in Arabic because neither dictionaries being used gives equivalents for them. An example is the expression engine surge. This is a new term which cannot be found in available Arabic technical dictionaries, and its meaning cannot be inferred from the immediate context. As it does not have a one-to-one equivalent in Arabic, the students rendered it as مشاكل المحركات, which literally means engine problems. However, the technical meaning of the word as it appeared in the al-Mamoon was تصوج ريش المحرك , which literally means curves in engine blades. This is because the students lacked previous knowledge about the same topic.

In most available bilingual dictionaries, the word serviceable may correspond to many words in Arabic قابل للصيانة or To illustrate the difference in meaning, consider the following three contexts for the same word: (1) the aircraft was placed unserviceable, (2) This was a servicing error. In (1), the word unserviceable is translated as أصبحت الطائرة غير صالحة للطبيران (literally: the aircraft has become unfit for flying), whereas in (2), it is used to refer to صيانة (literally: maintenance). In other words, one word in English can account for several in Arabic (one-to-many) and in the translation process students need to be aware of the different contexts and associated meanings and that a word can be used several times in a text with its meaning changing from one place to another. The dictionary meaning, خدمة الطائرات, as found in The Unifying Military Dictionary and A New Dictionary of Scientific and Technical Terms, is not always the appropriate choice.

In addition, the students also faced difficulties in handling English acronyms and abbreviations as these are rarely used in Arabic and hence the students have extremely limited exposure to them. It was, therefore, difficult for students to find the meanings of all the abbreviations used in the ST, because acronyms are sometimes used in the text without their full meanings given. Furthermore, because the students lacked the expert knowledge of the subject matter, it was very difficult for them to effectively decide what the acronym referred to in the text. Since abbreviations can have different semantic references, the choice of one meaning over another depends on the context and the expertise of the text user. For example, the abbreviation $F L$ as used in this sentence The pilot ... carried out a briefed reheat climb to FL 240 was wrongly interpreted as fighting level whereas in this context, it means that the pilot climbed to an altitude of 24000f. But the students translated it as تصل مستوى قتالي إلى 240 , which literally means the aircraft has to fight at a level of 240 . Another example is where the students left the English acronyms TGT, RPM and HP untranslated. This causes distortion to meaning in the translation where an Arab reader would not be able to understand the overall meaning of the sentence or paragraph in which this abbreviation occurs. Such a reader cannot understand the meaning of TGT, RPM and HP in the Arabic translation unless they are appropriately explained.

\section{Conclusion}

As outlined above, interlingual translation is a multi-layered process that involves reception of information (ST), the processing of this information, and the production of "new" information (TT). This process takes place in two different languages, which are used independently, but interfacing all the time. If this is not enough, in technical and scientific translation, this process is further complicated by the overuse of technical terms/words and collocations. These often assume meanings as per each use in each context of situation. Can dictionaries help UTSs? The limited in scope experiment carried out for the purpose of this study, shows that for students of translation to 'clone' the work of PTs, they need to free themselves from the 'spell of dictionaries and espouse context-sensitive and based meanings and information processing. As the experiment shows, this is valid for 
understanding of information in technical, such as military, texts and associated terminology, collocations and abbreviations/acronyms. Perhaps, to help UTSs mimic PTs, repeated instances of hands-on practice with technical institutions dealing with real instances of military translation, in our case, may be beneficial to students, institutions and society and can certainly reduce teacher-centered translation approaches in the Arab World.

\section{References}

Al Khatib, A. (1975). A new dictionary of petroleum and the oil industry. Beirut, Librarie Du Liban Publishers. Al Ma'amoon Royal Air Force of Oman Flight Safety Magazine. (1998). No. 3, Muscat.

Al-Ma'ani, M. (2012). A Learner-Centered Approach to Technical Translation in Undergraduate Programmes. Contributions from Arabic. The Linguistics Journal, 6(1), 205-217.

Al-Ma'ani, M. (2011). Localizing Technical Texts in Arabic through Translation with Special Reference to the Sultanate of Oman. STJ, 3, 55-72.

Asensio, R. (2007). Specialised Translation: A Concept in Need of Revision., Babel, 53(1), 48-55. http://dx.doi.org/10.1075/babel.53.1.05may

Byrne, J. (2012). Scientific And Technical Translation Explained. Manchester, UK. Saint Jerome Publishing.

Fraser, J. (1993). Public accounts: Using verbal protocols to investigate community translation. Applied Linguistics, 14(4), 322-43. http://dx.doi.org/10.1093/applin/14.4.325

Gouadec, D. (2007). Translation As A Profession. Amsterdam, John Benjamins. http://dx.doi.org/10.1075/btl.73

Kiraly, D. (2000). A Social Constructivist Approach to Translator Education. Manchester, UK, Saint Jerome Publishing.

Neubert, A. (2000). Competence in language, in languages, and in translation. In C. Schäffner \& B. Adab (Eds.), Developing translation competence (pp. 3-18). Philadelphia, PA, USA: John Benjamins Publishing Company. http://dx.doi.org/10.1075/btl.38.03neu

Nord, C. (2005). Text Analysis in Translation. Theory, Methodology, and Didactic. Application of a Model for Translation-oriented Text Analysis, Amsterdam, NewYork, Rodopi.

Schmitt, P. (2005). Grenzen der Kreativität. Lebende Sprachen, 3, 104-111. http://dx.doi.org/10.1515/les.2005.104

The Unifying Military Dictionary. (1970). Cairo, League of Arab States.

\section{Appendix 1.}

Source Text

\section{JAGUAR ENGINE SURGE}

\section{The Incident Report}

A Jaguar pilot accepted his aircraft at Seeb, for a return flight in formation to Thumrait. He noticed some damage to the reheat vapour guttering on his No. 2 Engine during his external inspection, and queried the cracks with the ground crew. The aircraft was placed unserviceable, but then declared serviceable by the ground crew some 40 minutes later.

The pilot departed from Seeb in formation, and carried out a briefed reheat climb to FL240. After 5-10 minutes at the cruising level, the pilot felt some vibration. The No.2 engine nozzle indication was seen to be fluctuating from $0-2$, and the vibration was sufficient to cause the No. 2 throttle to move about it's setting. He then heard and felt a loud bang from the No. 2 engine, and the No. 2 bleed valve light illuminated for a short time. A visual check of the No.2 engine was carried out by the pilot of another aircraft, but no obvious damage was seen. A further loud bang occurred, accompanied by an increase in TGT to $700 \mathrm{C}$ (the normal maximum temperature is 640C). The pilot moved the No.2 throttle to idle and then observed that the TGT was $650 \mathrm{C}$ with an RPM of 59\%. The associated bleed valve light was also on. After some 10 to 15 minutes the TGT dropped back to normal, and the pilot advanced the throttle again, to feel more vibration. The pilot made a PAN call and diverted to Seeb under the instructions of his leader. On landing a Seeb, even though he selected the throttle to HP off, the engine was still running, and it took the ground crew several attempts to shut it down, by exercising the throttle to HP off. 


\section{Target Text}

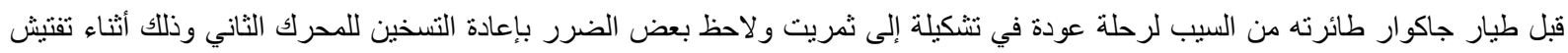

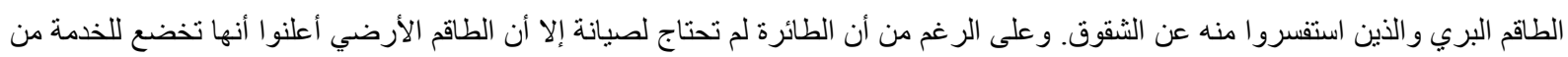
جديد بعد أربعين دقيقة.

ترك الطيار من السيب في التثكيلة وقام بالقفز في منطقة الطيران رقم 240 وبعد 5 إلى 10 دقائق راود الطيار شعورا بالتردد. وتم رؤية فتحة

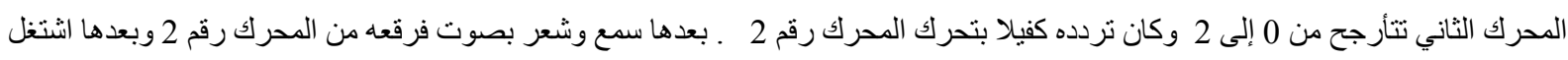

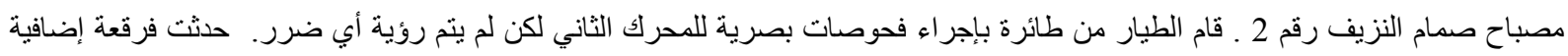

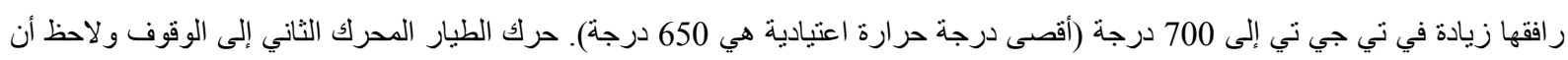

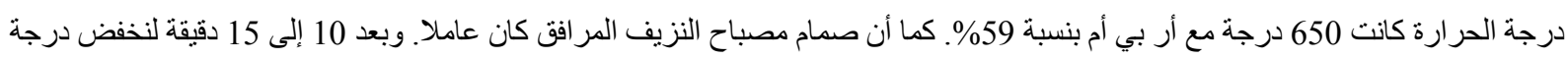

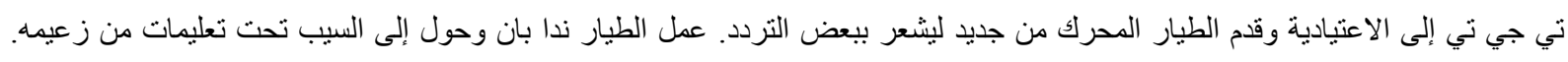

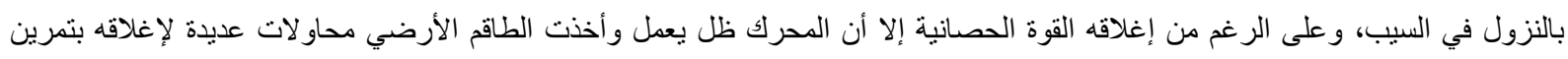
الدحرك للإغلاق.

\section{Copyrights}

Copyright for this article is retained by the author(s), with first publication rights granted to the journal.

This is an open-access article distributed under the terms and conditions of the Creative Commons Attribution license (http://creativecommons.org/licenses/by/3.0/). 